\title{
Chikungunya congénito y neonatal: Problemas emergentes en pediatría en Latinoamérica
}

\section{Congenital and neonatal Chikungunya: Emerging problems in pediatrics in Latin America}

\section{Señoreditor:}

Hemos leído con atención el reporte de caso publicado por Rolón y cols ${ }^{(1)}$, en el cual presentan el caso de un neonato de 16 días con cuadro de fiebre, rash, leucopenia y trombocitopenia con evolución tórpida que requirió soporte ventilatorio y empleo de antibioticoterapia de amplio espectro. Coincidimos con los autores en la importancia de considerar enfermedades emergentes como la infección por virus Chikungunya virus (CHIK), sin embargo queremos realizar algunas precisiones basadas en nuestra experiencia en Colombia y en particular precisar mejor en los conceptos relacionados a las diferencias entre infección congénita y neonatal, no presentados en el caso de Rolón y cols, pero que tienen importantes implicaciones en la discusión, así como por la vigilancia que en el embarazo debe hacerse de esta infección, que puede ser de gravedad en la embarazada y en el neonato. Es bueno tener en cuenta que la media de inicio de los síntomas en neonatos es de cuatro días (rango de 3-7), por eso cuando se tiene identificado que la madre tiene sintomatología, cuatro días antes del parto y tres días después estos recién nacidos deben hospitalizarse en una Unidad de Cuidados Intensivos Neonatales ${ }^{(2)}$.

Como es sabido CHIK se ha extendido en múltiples países de la región, particularmente durante 2014 y en lo que va de $2015^{(3,4)}$. De acuerdo a las cifras que reporta la Organización Panamericana de la Salud (OPS), durante 2014 se reportaron en Paraguay 1 caso importado y 7 casos confirmados de transmisión autóctona. Sin embargo, ya para 2015, hasta la semana epidemiológica 27 (10 de julio de 2015), se habían reportado a la OPS 1759 casos sospechosos y 813 confirmados.

La historia natural de la infección por CHIK ha sido ampliamente descrita, considerando manifestaciones clínicas, diagnósticos diferenciales, factores de riesgo de severidad, consecuencias a corto y largo plazo, donde como se menciona por los autores ${ }^{(2)}$ preocupa el compromiso articular compartido por diferentes alfavirus y el cual representa un espectro evolutivo variable que si bien ha sido relacionado con factores de riesgo como la preexistencia de enfermedades crónicas articulares. Su patogénesis molecular puede generar un desenlace crónico independiente de los antecedentes del paciente ${ }^{(5)} y$ generando un impacto social considerando la discapacidad que se genera ${ }^{(6)}$.

En pediatría, el diagnóstico diferencial con infección por dengue virus ha sido motivo de múltiples estudios, considerando la complejidad que existe en el interrogatorio y la similitud en la evolución de las manifestaciones clínicas en común. Llama la atención en contraste con lo presentado por los autores que en menores los cuadros febriles han sido más prolongados en la infección por dengue y las manifestaciones cutáneas no han presentado diferencias significativas en los cuadros no severos entre ambas entidades ${ }^{(7)}$, siendo el punto clave el mayor compromiso articular en la infección por CHIK, la trombocitopenia y linfopenia que puede presentarse hasta en el $50 \%$ de los menores ${ }^{(8)}$, y esta última no presentada por el paciente. 
En neonatos el asunto es aún más complicado, pues en lo concerniente a la infección perinatal, que puede ocurrir durante la gestación conllevando a la infección en el recién nacido en al menos $20 \%$ de los casos (congénita) o en el período neonatal, debe diferenciarse entre la infección adquirida durante el embarazo a la que puede ocurrir por la picadura del mosquito a un recién nacido, dado que el período de incubación van en un rango de 1-12 días (usualmente de 3-7 días). Por lo cual un neonato de 12 días en adelante podría corresponder con un caso de infección neonatal, pero en una edad inferior, improbablemente, correspondiendo posiblemente a una infección congénita.

La infección congénita fue descrita por primera vez en 2005. Esta se ha relacionado con la presencia de viremia en la madre durante una semana antes del parto, desarrollando el neonato infectado sintomatología en una rango promedio de 3 a 7 días, sin embargo se han reportado casos en neonatos de hasta de 25 días, siendo las manifestaciones clínicas más frecuentes en este grupo etario petequias, trombocitopenia, linfopenia, fiebre, rash y edema ${ }^{(9)} \mathrm{y}$ siendo complicado definir si se trata de una infección adquirida o transmitida, a pesar de la negatividad de la IgM de la madre.

En este sentido, con respecto al diagnóstico, es recomendable en este grupo poblacional realizar durante los primeros cinco días de la infección PCRRT y en muestras obtenidas después IgM e IgG antiCHIK por ELISA, pruebas que deben ser de igual forma realizadas a la madre con el objetivo de descartar la transmisión materno-fetal ${ }^{(8)}$. Si bien la IgM para CHIK tiene una sensibilidad promedio de $90,3 \%$, su especificidad es menor, pudiendo presentarse falsos positivos en el contexto del caso presentado por sepsis incluso de origen bacteriano ${ }^{(10)}$, a pesar de la negatividad de los hemocultivos pero la buena respuesta a la antibioticoterapia de amplio espectro.

Es de señalar que la mayoría de los casos de infección por CHIK reportados en la literatura con manifestaciones que involucran el sistema nervioso central, implican extenso compromiso en los menores, generando falla multiorgánica y una característica hiperpigmentación cutánea, lo cual implica realización de neuroimágenes y análisis de líquido cefalorraquídeo, lo cual en el caso presentado pudiese haber aportado en el diagnóstico diferencial o en apoyo para la confirmación del caso. Siendo importante a manera de recomendación el seguimiento a esta menor, dado que aunque llama la atención la pronta recuperación, las secuelas neurocognositivas de la encefalitis desarrollada en el contexto de infección por CHIK han sido descritas ${ }^{(8,9)}$.

En nuestra reciente experiencia en Colombia ${ }^{(11)}$, documentando la primera serie de siete embarazadas con infección confirmada por CHIK que transmitieron la infección a sus ocho neonatos (un embarazo gemelar); la infección congénita es de mayor frecuencia a la previamente reportada en otras regiones del mundo. En ellos se observó con preocupación que a pesar de haberse realizado en $75 \%$ de ellos cesárea, no mostró impacto en la prevención de la infección congénita. En muchas series, la cesárea no mostró impacto en la disminución de la trasmisión congénita. Lo mismo da realizar cesárea que el parto vaginal. Cabe mencionar además, que la enterocolitis necrotizante, en nuestra serie se presentó en $38 \%$, siendo el porcentaje más alto citado en la literatura. En adición, la miocarditis y la meningoencefalitis en $25 \%$ respectivamente. Con todo ello, estos pacientes neonatales tuvieron una tórpida evolución que conllevó a la muerte en tres de los ocho recién nacidos (letalidad de $37,5 \%)^{(11)}$.

Finalmente, es de extrema importancia en el contexto de la reemergencia de estas entidades infecciosas compartir con la comunidad científica las experiencias vividas en todas las latitudes, sin embargo el ejercicio diagnóstico debe ser estricto para aportar de la mejor forma a los lectores.

\section{Álvaro E. Mondragón-Cardona ${ }^{(1,2)}$, Wilmer E. Villamil-Gómez ${ }^{(3,4)}$, Alfonso J. Rodriguez- Morales $^{(1,3)}$}

1. Grupo de Investigación Salud Pública e Infección, Facultad de Ciencias de Salud, Universidad Tecnológica de Pereira, Pereira, Risaralda, Colombia.

2. Postgrado de Medicina Interna, Hospital Universitario Hernando Moncaleano Perdomo, Facultad de Salud, Universidad Surcolombiana, Neiva, Huila, Colombia.

3. Comité de Zoonosis y Fiebres Hemorrágicas, Asociación Colombiana de Infectología, Bogotá, Colombia.

4. Dirección de Investigación, Hospital Universitario de Sincelejo (HUS), Sincelejo, Sucre, Colombia. E-mail: arodriguezm@utp.edu.co 


\section{REFERENCIAS}

1. Gerardin P, Barau G, Michault A, Bintner M, Randrianaivo H, Choker G, Lenglet $Y$, Touret $Y$, Bouveret A, Grivard P, Le Roux K, Blanc S, Schuffenecker I, Couderc T, Arenzana-Seisdedos F, Lecuit M, Robillard PY. Multidisciplinary prospective study of mother-to-child chikungunya virus infections on the Island of La Re' union. PLoSMed. 2008;5:e60.

2. Rolón P, Fonseca R, Genes L, Pereira S, Zapatta L, Benítez G. Chikungunya adquirida en Recién Nacidos: reporte de caso. Pediatr (Asunción). 2015;42:42-47.

3. Ogden NH, Milka R, Caminade C, Gachon P. Recent and projected future climatic suitability of North America for the Asian tiger mosquito Aedes albopictus. Parasit Vectors. 2014;7:532.

4. Rodriguez-Morales AJ, Cardenas-Giraldo EV, Montoya-Arias CP, Guerrero-Matituy EA, Bedoya-Arias JE, Ramirez-Jaramillo V, Villamil-Gómez WE. Mapping chikungunya fever in municipalities of one coastal department of Colombia (Sucre) using geographic information system (GIS) during 2014 outbreak: Implications for travel advice. Travel Med Infect Dis. 2015;13(3):256-58.

5. Assuncao-Miranda I, Cruz-Oliveira C, Da Poian AT. Molecular mechanisms involved in the pathogenesis of alphavirus-induced arthritis. Biomed Res Int. 2013;2013:973516.
6. Rodriguez-Morales AJ, Cardona-Ospina JA, VillamilGomez W, Paniz-Mondolfi AE. How many patients with post-chikungunya chronic inflammatory rheumatism can we expect in the new endemic areas of Latin America? Rheumatol Int. 2015. doi:10.1007/s00296-015-3302-5

7. Chipwaza B, Mugasa JP, Selemani M, Amuri M, Mosha F, Ngatunga SD, Gwakisa PS. Dengue and Chikungunya fever among viral diseases in outpatient febrile children in Kilosa district hospital, Tanzania. PLoS Negl Trop Dis. 2014;8(11):e3335.

8. Ritz N, Hufnagel M, Gerardin P. Chikungunya in children. Pediatr Infect Dis J. 2015;34(7):789-91.

9. Gupta D, Bose A, Rose W. Acquired neonatal Chikungunya encephalopathy. Indian J Pediatr. 2015. doi:10.1007/s12098-015-1751-1

10. Thein S, La Linn M, Aaskov J, Aung MM, Aye M, Zaw A, Myint A. Development of a simple indirect enzymelinked immunosorbent assay for the detection of immunoglobulin $\mathrm{M}$ antibody in serum from patients following an outbreak of chikungunya virus infection in Yangon, Myanmar. Trans R Soc Trop Med Hyg. 1992;86(4):438-42.

11. Villamil-Gómez W, Alba-Silvera L, Menco A, Gonzalez-Vergara A, Molinares-Palacios T, BarriosCorrales M, Rodriguez-Morales AJ. Congenital Chikungunya Virus Infection in Sincelejo, Colombia: a case series. J Trop Pediatr. 2015; doi: 10.1093/tropej/fmv051 